REGARDS

SUR LEECONOMIE ALLEMAND

BULLETIN ECONOMIQUE DU CIRAC
Regards sur l'économie allemande

Bulletin économique du CIRAC

98-99 | 2010

Varia

\title{
Fiscalité : les impôts et taxes les plus absurdes
}

Isabelle Bourgeois

\section{CpenEdition}

Journals

Édition électronique

URL : http://journals.openedition.org/rea/4200

DOI : $10.4000 /$ rea.4200

ISBN : 978-2-8218-0892-8

ISSN : 1965-0787

Éditeur

CIRAC

Édition imprimée

Date de publication : 26 octobre 2010

Pagination : 81

ISSN : 1156-8992

Référence électronique

Isabelle Bourgeois, "Fiscalité : les impôts et taxes les plus absurdes", Regards sur l'économie allemande [En ligne], 98-99 | octobre 2010, mis en ligne le 05 novembre 2010, consulté le 15 septembre 2020. URL : http://journals.openedition.org/rea/4200

Ce document a été généré automatiquement le 15 septembre 2020.

(C) CIRAC 
Fiscalité : les impôts et taxes les plus absurdes

Isabelle Bourgeois 
1 A intervalles réguliers, lorsque sont débattues d'éventuelles réformes fiscales, la presse allemande se fait un plaisir d'aller débusquer dans les Länder et communes (ils ont une large autonomie en matière fiscale) les prélèvements les plus absurdes ou les plus cocasses. Il faut dire qu'elle n'est pas la seule, la Cour des Comptes fédérale et la Fédération allemande des contribuables se livrant régulièrement au même exercice. Voici donc un petit aperçu de l'inventivité dont font preuve les communes pour renflouer leurs caisses mises à mal par la récession, puisé dans un échantillon publié le $1^{\text {er }}$ octobre par le quotidien économique Handelsblatt (www.handelsblatt.com).

2 La «taxe sur les chiens » n'est plus à présenter, c'est un classique de la fiscalité communale, et elle rapporte gros (par exemple un encours de 5,3 millions $€$ aux communes de Thuringe en 2009, à en croire le portail www.otz.de des quotidiens Thüringer Allgemeine et Thüringer Landeszeitung). Depuis le $1^{\mathrm{er}}$ octobre, Cologne prélève une "taxe sur les lits» (5\% par nuitée à verser par les hôtels) dont l'encours attendu (7 millions $€$ par an) alimentera son budget Culture. Berlin a une formule identique ; Hambourg projette une "taxe de culture " pour 2011, calquée sur le même modèle, et censée rapporter quelque 10 millions $€$ par an. Quant à Essen, la ville a décidé en septembre de frapper les propriétaires de solariums d'un "impôt bronzage » (20€ par mois et par appareil). Plus convenue en comparaison est cette extensionde la classique " taxe sur le divertissement " (Vergnügungssteuer) des communes (elle concerne toutes les manifestations festives): la "taxe sexe" que paient depuis 2003 les prostituées à Cologne ; la ville d'Oberhausen vient de s'en inspirer ( $6 €$ par jour). Mais la palme de la créativité revient assurément au village de Niederzimmern (Thuringe), où la mairie vend aux habitants $50 €$ pièce les nids de poule, avec pour contrepartie l'apposition d'une plaque commémorative (avec libre choix du texte) dans un tronçon de rue venant d'être refait. Les Allemands ne manquent visiblement pas d'humour : 257 nids de poule auraient déjà trouvé preneur... (IB)

\section{INDEX}

Mots-clés : fiscalité, politique fiscale, impôt, taxe 